\title{
Inflammatory fibroid polyp of caecum. A case report
}

\author{
Mohammad Shahid Iqbal ${ }^{1}$ M.D, Aisha Tabassum ${ }_{\text {M.D }}^{2}$ \\ 1.Department of Pathology, Kamineni institute of medical sciences/DRNTRUHS,India \\ 2.Department of Pathology,Kamineni institute of medical sciences/DRNTRUHS,India
}

\begin{abstract}
Inflammatory fibroid polyps are rare benign lesions that occur throughout the gastrointestinal tract.We present a case of inflammatory fibroid poly occurring in caecum. A 26 year old female presented with intestinal obstruction. Caecum showed a polypoidal growth.External surface of polyp was smooth with focal areas of ulceration. Histologically,inflammatory fibroid polyp was the diagnosis.Conclusion:Inflammatory fibroid polyp should be considered as one of the differential diagnosis of pedunculated polyps in proximal colon and caecum.
\end{abstract}

Keywords:Caecum, Eosinophils, Fibroblast, Polyp

\section{Introduction}

Inflammatory fibroid polyps are histologically and clinically benign lesions that occur throughout the gastrointestinal tract.They are most common in the gastric antrum and the terminal ileum but have been reported in diverse sites including the esophagus and duodenum. Inflammatory fibroid polyps occur relatively uncommonly in the colorectum ${ }^{1,2,3}$. The disease has no sex predilection and peak prevalence is in the $5^{\text {th }}$ and $6^{\text {th }}$ decade of life ${ }^{2}$. Here we report a case of inflammatory fibroid polyp arising in the caecum in a young patient.

\section{Case report}

A 26 year old female patient presented with intestinal obstruction. Endoscopy showed a polypoidal lesion in the caecum. Resected caecum with the polypoidal lesion was examined. The polyp with stalk measured $5 \times 5 \mathrm{~cm}$ (Fig.1). External surface of the polyp was smooth with focal areas of ulceration. Cut surface was grey white with myxoid areas. Microscopy revealed loose edematous stroma consisting of eosinophils,lymphocytes and plasma cells(Fig. 2 \& 3). The pedunculated polyp was diagnosed as inflammatory fibroid polyp of caecum.

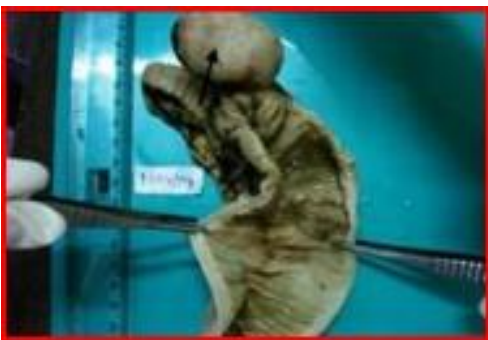

Fig:1.Polypoidal growth arising in caecum

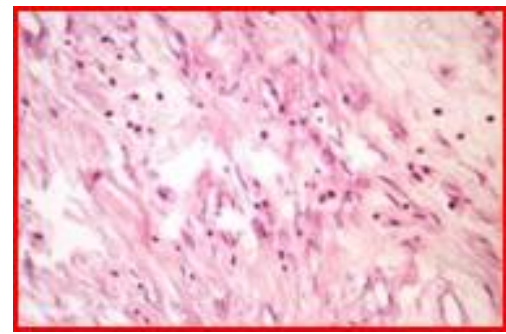

Fig:2.Edematous stroma,bland spindle cells and inflammatory cells. 


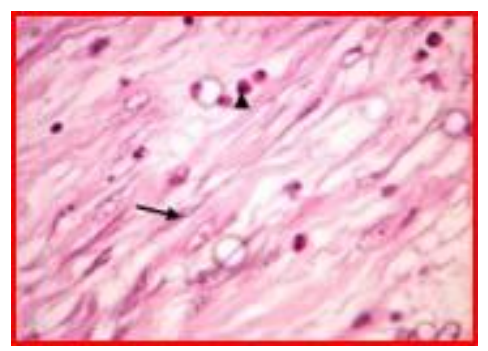

Fig:3.Bland spindle cells(arrow) and eosinophil(arrow head)

\section{Discussion}

Inflammatory fibroid polyp is a relatively rare disorder which is thought to be clinically and histologically benign and was first described as 'polypoid fibroma' in 1920 by Konjetzny ${ }^{4}$. These are rare submucosal lesions of the gastrointestinal tract. It usually appears as a smooth sessile or pedunculated polyp and follows a benign course ${ }^{5}$. These polyps rarely occur in the large intestine ${ }^{6}$. Endoscopically, colonic inflammatory fibroid polyps appear submucosally and range in size from 1.5 to $7 \mathrm{~cm}$. In the majority of cases,the overlying colonic mucosa is ulcerated ${ }^{1}$. Study by Nakase et al ${ }^{7}$ described 25 cases of inflammatory fibroid polyps in the colon. They described appearance on macroscopy as pedunculated in $68 \%$ of cases and sessile in $32 \%$ of cases. In their study,the sites of inflammatory fibroid polyps were predominantly in the proximal colon with $52 \%$ of cases in ascending colon and caecum ${ }^{7}$. Inflammatory fibroid polyps can present in many different ways including pain,bleeding,anemia,persistent polyp intussusceptions and intestinal obstruction ${ }^{8}$. C Ng et al ${ }^{2}$ reported a similar case to ours but in an older patient arising in caecum. Microscopic analysis of these polyps revealed abundant fibroblasts arranged in whorls around blood vessels with prominent inflammatory cells ${ }^{9}$. The inflammatory infiltrate is usually dominated by eosinophils. Lymphocytic aggregate lacking germinal centres may also present and polyclonal plasma cells, histiocytes and neutrophils may be seen as well ${ }^{8}$.

\section{Conclusion}

Inflammatory fibroid polyp in caecum are rare.This entity should be included as one of the differential diagnosis of pedunculated polyps in caecum.

\section{References}

[1]. Abraham SC, Burgart LJ, Odze RD. Polyps of the large intestine. Chapter 15 In: Odze RD, Goldblum JR, Crawford JM. Editors. Surgical pathology of the GI tract, liver, biliary tree and pancreas. Saunders, 2004;p.327-379

[2]. Ng C, Lam KY, Gupta TS, Ho YH. Inflamamtory fibroid polyp of the caecum in a patient with neurofibromatosis. Ann Acad Med Singapore 2004;33:797-9

[3]. De la Plaza R, Picardo AL, Cuberes R, Jara A, Martinez-Penalver I, Villanueva MC, Medina M, Alias D, Osorio S,Pacheco E, Suarez A. Infl ammatory fi broid polyps of the large intestine. Dig Dis Sci 1999; 44: 1810-1816

[4]. Konjetzny GE. Uber Magenfi brome. Beitr Klin Chir 1920; 119: 53-61

[5]. Hirasaki S, Matsubara M, Ikeda F, Taniguchi H, Suzuki S. Inflammatory fibroid polyp occurring in the transverse colon diagnosed by endoscopic biopsy. World J Gastroenterol 2007 July;21:13(27).3675-3676

[6]. Blackshaw AJ, Levison DA. Eosinophilic infiltrates of the gastrointestinal tract. J Clin Pathol 1986; 39: 1-7

[7]. Nakase H, Mimura J, Kawasaki T, Itani T, Komori H, Hashimoto K, Okazaki K, Chiba T. Endoscopic resection of small inflammatory fibroid polyp of the colon. Intern Med 2000; 39: 25-27

[8]. Gupta RS. Inflammatory fibroid polyps of the gastrointestinal tract. Pathologe 2001;22:333-8.

[9]. Kuestermann SA, Saleeb SF, Teplick SK. General case of the day. Jejunal intussusception caused by an inflammatory fibroid polyp (IFP). Radiographics 1999;19:539-41 